\title{
8
}
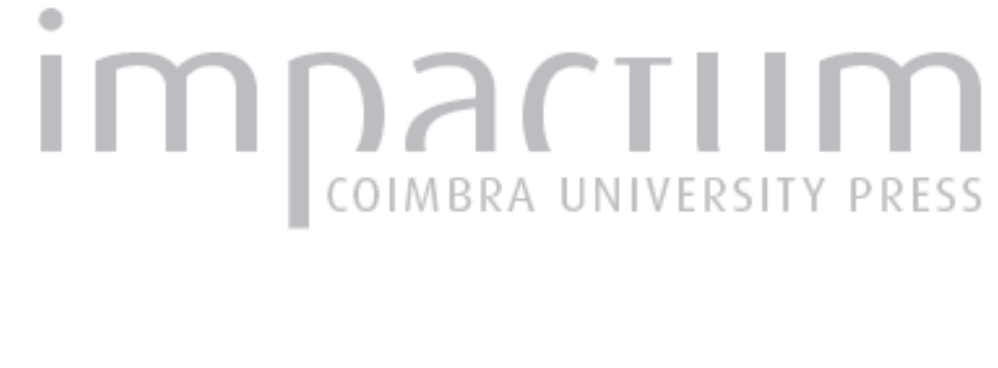

\section{A analogia entre cidade e alma na república de Platão: uma discussão com leo Strauss}

Autor(es): $\quad$ Motta, Guilherme Domingues da Publicado por: Universidade Católica de Petrópolis; Instituto Brasileiro de Informação

URL

persistente:

URl:http://hdl.handle.net/10316.2/33096

DOI:

DOI:http://dx.doi.org/10.14195/1984-6754_2_3

Accessed : $\quad$ 26-Apr-2023 11:07:01

A navegação consulta e descarregamento dos títulos inseridos nas Bibliotecas Digitais UC Digitalis, UC Pombalina e UC Impactum, pressupõem a aceitação plena e sem reservas dos Termos e Condições de Uso destas Bibliotecas Digitais, disponíveis em https://digitalis.uc.pt/pt-pt/termos.

Conforme exposto nos referidos Termos e Condições de Uso, o descarregamento de títulos de acesso restrito requer uma licença válida de autorização devendo o utilizador aceder ao(s) documento(s) a partir de um endereço de IP da instituição detentora da supramencionada licença.

Ao utilizador é apenas permitido o descarregamento para uso pessoal, pelo que o emprego do(s) título(s) descarregado(s) para outro fim, designadamente comercial, carece de autorização do respetivo autor ou editor da obra.

Na medida em que todas as obras da UC Digitalis se encontram protegidas pelo Código do Direito de Autor e Direitos Conexos e demais legislação aplicável, toda a cópia, parcial ou total, deste documento, nos casos em que é legalmente admitida, deverá conter ou fazer-se acompanhar por este aviso. 



Revista do Centro de Teologia e Humanidades ISSN 1984-6754






\section{A analogia entre cidade e alma na República de Platão: uma discussão com Leo Strauss}

\section{Guilherme Domingues da Motta ${ }^{1}$}

Resumo: Em City and Man, Leo Strauss incide em um grave erro de interpretação da República, de Platão, cuja raiz é uma compreensão equivocada da analogia entre cidade e alma presente na obra. O que a análise do texto de Strauss mostra é que, ao conferir um caráter demasiadamente estrito à analogia, acaba por adotar uma concepção sobre a classe dos artesãos presente na cidade construída com o lógos na República que é, no mínimo, injusta. Strauss nomeia os indivíduos pertencentes à essa classe como "money-makers" e os caracteriza como incapazes de ter as virtudes cívicas fundamentais. A retificação da interpretação de Strauss depende, fundamentalmente, da consideração do papel da educação pela mousiké e pela gymnastiké apresentadas na República e da intenção do autor, Platão, de que seja estendida a todas as classes. Só tal extensão pode resolver os aparentes impasses presentes na obra, os quais levam Strauss a se desviar de sua correta interpretação.

Abstract: In City and Man, Leo Strauss incurs in a serious misinterpretation of Plato's Republic, which is rooted in his failure to properly understand the analogy between city and soul as presented in this Plato's work. What an analysis of Strauss text shows is that by taking the strictness of the analogy beyond what is appropriate, he construes unfairly the class of artisans which belongs to the city constructed by Plato in the Republic. Strauss construes the individuals belonging to that class as "money-makeres" and as people unable to have within their souls the fundamental civic virtues. Rectifying this view depends on taking into account the role of the education by mousiké and gymanstiké proposed in

1 Possui Grauação (1993), Mestrado (2000) e Doutorado em Filosofia pela Universidade Federal do Rio Janeiro (2010). Atualmente é Professor Assistente da Universidade Católica de Petrópolis.

http://www.ucp.br/htmlljoomlaBR/synesis/synesis.htm 
the Republic and that Plato intended it to be extended to all classes in the city. This extension alone can solve the apparent impasses in the Republic which lead Strauss to his misinterpretation of the work.

É conhecida a existência na República de Platão de uma analogia entre a cidade que Sócrates propõe que se construa com o lógos nessa obra e a alma humana.

O que dá ensejo à construção dessa cidade é a necessidade de saber o que é a justiça, uma vez que se pretende defender a tese segundo a qual é melhor para o homem ser justo do que injusto; tese esta que foi atacada antes, tanto por Trasímaco, quanto por Gláucon e Adimanto, todos, em certa medida, veiculando as opiniões da maioria, segundo a qual é mais vantajoso ser injusto.

É por não terem conseguido antes chegar a definir o que é a justiça que Sócrates e seus interlocutores consideram que seria melhor examinar primeiro o que ela seria numa cidade, tal como alguém que, tendo a vista fraca, tivesse de ler de longe letras pequenas, recorreriam primeiro à leitura numa escala maior e depois retornariam à questão da justiça e da injustiça no homem para ver se o resultado era o mesmo ${ }^{2}$.

Uma vez aceita essa proposta, Sócrates estabelece como o princípio de fundação da cidade o fato de que os seus habitantes não são auto-suficientes e necessitam de muitas coisas. ${ }^{3}$

Assim, é porque é preciso satisfazer essas necessidades que os homens se reúnem em cidades, convictos de que esta é a melhor maneira de obterem aquilo de que precisam: alimento, habitação, vestuário, etc...

Para a obtenção de tantas coisas a melhor solução é que haja diferentes pessoas que se ocupem cada uma da produção de uma coisa, de modo que possam partilhar com os outros o resultado do seu ofício, beneficiando-se, da mesma forma, do ofício alheio. Essa divisão de funções é fundada na natureza

\footnotetext{
2 PLATÃO. República, 368b.

3 PLATÃo. República, 369b.

http://www.ucp.br/html/joomlaBR/synesis/synesis.htm
} 
mesma dos habitantes da cidade, que em cada um é diferente e apropriada para a melhor execução de uma única função. ${ }^{4}$ Os que produzem esses bens necessários constituem a classe que se chamará aqui de "classe dos artesãos".

Seguindo esse princípio, Sócrates, com a ajuda de seus interlocutores, continua a construção da cidade, fazendo-a crescer até que todas as necessidades fundamentais dos seus habitantes estejam atendidas, de modo que possam viver, sem luxo, mas com conforto, "num convívio agradável uns com os outros", "passando a vida em paz e com saúde". ${ }^{6}$

Porém, a essa altura da discussão Gláucon intervém por considerar que Sócrates está organizando uma cidade de porcos, que não precisam senão da sua foragem para estarem satisfeitos. Gláucon reivindica aquilo que é o costume nas cidades "reais": leitos onde se recline, iguarias, enfim, tudo aquilo que Sócrates imediatamente compreende como estando presente numa cidade luxuriosa. ${ }^{7}$

Sócrates não julga má idéia que se passe a estudar uma cidade assim, pois nessa cidade luxuriosa e inchada de humor talvez se veja surgir mais depressa a justiça e a injustiça do que na primeira, que chama de cidade sã. ${ }^{8}$ É, portanto, essa segunda cidade que se passará a analisar. Nesse processo de "inchá-la" acrescentar-se-á a ela tudo o que na outra era supérfluo:

(...) leitos, mesas e outros objetos e ainda iguarias, perfumes e incenso, cortesãs e guloseimas, e cada uma destas coisas em toda a sua variedade;(...) ir-se-á buscar a pintura e o colorido, e entender-se-á que se deve possuir ouro, marfim e preciosidades dessa espécie. ${ }^{9}$

\begin{tabular}{ll}
\hline 4 & PLATÃO. República, 369c-370b. \\
5 & PLATÃO. República, 372b. \\
6 & PLATÃO. República, 368b. \\
7 & PLATÃO. República, 372 d-e. \\
8 & PLATÃO. República, 372e. \\
9 & PLATÃO. República, 373a.
\end{tabular}

http://www.ucp.br/htmlljoomlaBR/synesis/synesis.htm 
Ainda serão necessárias muitas pessoas que não havia na outra:

(...) caçadores de toda espécie e imitadores, muitos dos quais são os que se ocupam de desenho e cores, muitos outros da arte das musas, ou seja, os poetas e seus servidores: rapsodos, atores, coreutas, empresários, artífices que fabriquem toda espécie de utensílio, sobretudo adereços femininos. ${ }^{10}$

A cidade terá ainda: pedagogos, amas, governantas, azafatas, cabeleireiros, cozinheiros, marchantes, porqueiros, toda espécie de gado e, sobretudo, médicos, que se tornarão necessários devido ao tipo de vida que se levará aí. ${ }^{11}$

Ainda, pelo seu próprio caráter, o qual implica que se esteja sempre necessitando de mais coisas, essa cidade precisará também de um exército, pois não só precisará expandir-se, como, também, proteger-se de outras cidades semelhantes. $^{12}$

Como assentado no início da construção da cidade, antes mesmo que ela começasse a "inchar", os guerreiros, seguindo o princípio da divisão de funções segundo a natureza, se ocuparão de uma única tarefa. Esses guerreiros, que passarão a ser chamados de guardiões, devem, portanto, ter uma natureza apropriada à custódia da cidade. ${ }^{13}$

O guardião deve ser perspicaz, rápido, forte, valente e animoso (thymoeidés), uma vez que o ânimo “é invencível e indomável”, não conhecendo as almas possuídas por ele nem medo, nem derrota em qualquer circunstância. ${ }^{14}$

Porém, a essa qualidade de ser animoso (thymoeidés) deve aliar-se uma

\begin{tabular}{ll}
\hline 10 & PLATÃO. \\
11 & República, 373b. \\
12 & PLATÃO. República, 373b. \\
13 & PLATÃO. República, , $373 \mathrm{~d}$. \\
14 & PLÁblica, 374b-e. \\
&
\end{tabular}

http://www.ucp.br/htmlljoomlaBR/synesis/synesis.htm 
outra, que lhe é oposta: a brandura, pois hão de ser brandos com os compatriotas e acerbos para com os inimigos ${ }^{15}$, tais como os cães de boa raça. Por isso, podese dizer que são amigos do saber (philomatés), uma vez que não distinguem uma visão amiga de outra inimiga senão pela circunstância de a conhecer ou não. ${ }^{16}$

É neste ponto que Sócrates faz a pergunta que introduzirá o tema do qual dependerá, conforme se procurará mostrar aqui, a possibilidade mesma de se chegar à definição de justiça (dikaiosýne) a que se chega no final do livro IV: "Mas de que maneira é que hão-de criar e educar (threpsontai paideuthesontai) estes homens? ${ }^{17}$

Sócrates passa então a tratar de como educar esses homens e elege a forma consagrada pela tradição: a música (mousiké) e a ginástica (gymnastiké $)^{18}$. Essa educação, que se chamará aqui de "educação primária", leva a uma "purgação" da cidade, da qual são expurgados todos os excessos admitidos por ocasião de seu "inchaço".

Depois de tratar da educação da cidade, Sócrates introduz, ao lado de artesãos e de guardiões a última classe, que a completa: a dos governantes. Só então passa a examinar a cidade formada em busca de identificar nela a justiça.

Sócrates parte de dois pressupostos: o primeiro é de que a cidade que acabaram de fundar é totalmente boa (teléos agathén) e o segundo é de que disto decorre que ela seja sábia (sophé), corajosa (andreía), temperante (sóphron) e justa (dikaía). ${ }^{19}$

\footnotetext{
15 PLATÃO. República, 375c.

16 PLATÃO. República, 375d-376b.

17 PLATÃO. República, 376c.

18 A mousiké compreendia tudo o que estava envolvido na narrativa poética: os conteúdos versificados, os acompanhamentos musicais, a atitude corporal e a forma de recitação. A gymnanstiké, por sua vez, compreendia tudo o que se relacionava com a excelência do corpo, inclusive a dieta. Não se dispõe de espaço aqui para um descrição detalhada desse modelo de educação "primária". Para uma descrição completa dessa educação, ver PLATÃO. República, 376c-412b. Sobre se essa educação se destina somente aos guardiões ou a todas as classes, ver MOTTA, Guilherme Domingues da. A educação como fundamento da unidade e da felicidade da polis na República, de Platão. Rio de Janeiro: IFCS/ UFRJ, 2010.

19 PLATÃO. República, 427e.
}

http://www.ucp.br/html/joomlaBR/synesis/synesis.htm 
Sempre tendo em vista a importância da educação primária como fundamental para sua existência ${ }^{20}$, Sócrates identifica na cidade as três primeiras virtudes (sabedoria, coragem e temperança) e, após convocar Gláucon a, junto com ele, esforçar-se na difícil tarefa de enxergar onde se encontra a justiça, a identifica como sendo o princípio mesmo que, na fundação da cidade, logo no começo da discussão, estabeleceu-se como aquele que devia ser observado em todas as circunstâncias: o de que "cada um deve ocupar-se de uma função na cidade: aquela para a qual sua natureza é mais adequada." ${ }^{21}$

Passando à alma, Sócrates parte do pressuposto de que "o homem justo, no que respeita a noção de justiça, nada diferirá da cidade justa, mas será semelhante a ela.". ${ }^{22}$ Assim, sendo o que tornava a cidade justa o fato de haver dentro dela três espécies de naturezas que desempenhavam (práttein) cada uma a tarefa que lhe era própria, a questão que se coloca é a de saber se a alma (psyché) também possui três elementos constituintes..$^{23}$

Que seja assim, Sócrates infere do fato de que a irascibilidade, o gosto pelo saber, ou o amor das riquezas, pelos quais diferentes cidades se tornaram conhecidas, só podem provir de seus habitantes. ${ }^{24}$

Porém, é preciso determinar se cada ação é executada por um mesmo elemento, ou se cada ação por um dos elementos que lhe é próprio, visto que são três. ${ }^{25}$ Sócates, demonstra que são três, e os distingue da seguinte forma: há um pelo qual compreendemos, o elemento racional (logistikón), outro pelo qual irritamo-nos, o elemento irascível, (thymoeidés) e outro pelo qual desejamos os prazeres relativos à bebida, à alimentação e ao sexo, o elemento apetitivo (epithymetikón). ${ }^{26}$

\footnotetext{
20 Para o processo pela qual se identificam na cidade a sabedoria, a coragem e a temperança, ver PLATÃO. República, 427c-432b.

21 PLATÃO. República, 433a.

22 PLATÃO. República, 435b

23 PLATÃO. República, 435 b.

24 PLATÃO. República, 435.

25 PLATÃO. República, 436a.

26 PLATÃO. República, 436b.
}

http://www.ucp.br/html/joomlaBR/synesis/synesis.htm 
A maneira como Leo Strauss interpreta, em City and $\mathrm{Man}^{27}$, a analogia entre cidade e homem presente na República envolve a admissão, que qualquer leitor da obra deve aceitar, de que há três classes na cidade e de que há no homem três elementos na alma que guardam certa analogia com aquelas.

Porém, a maneira como se refere a essas classes e elementos indica que para ele o homem é o fator prevalente na analogia e que a cada elemento presente na alma deve corresponder uma classe na cidade que tenha fundamentalmente as características do elemento da alma correspondente.

A maneira como esse autor se refere às classes na cidade diz muito sobre como sua maneira de ver a analogia entre cidade e homem. Note-se como Strauss se refere a elas no âmbito da afirmação da própria analogia:

Uma consideração provisória da alma parece estabelecer os requisitos mencionados: a alma contem desejo, irascibilidade e razão, justamente como a ciade consiste de money-makers ${ }^{28}$, [khrematistikós] guerreiros e govenantes. ${ }^{29}$

Chama a atenção a opção de Strauss, como de outros comentadores da República $^{30}$, de nomear a classe dos artesãos como money-makers ou produtores de riquezas, como se essa fosse uma classe voltada para o lucro, quando na verdade, a riqueza foi excluída por Sócrates da cidade e muitas vezes citada como

$\overline{27}$ STRAUSS, Leo. The City and Man. Chicago: The University of Chicago Press, 1978.

28 Optou-se aqui por não traduzir money-makers para que fique clara a opção de Strauss ao nomear a classe dos artesãos como aquela voltada para a riqueza. Mesmo na tradução mais favorável possível de money-makers por "produtores de riquezas" e mesmo que se considere que o que a classe dos artesãos faz é produzir os bens de subsistência necessários para todos e isso possa ser chamado "riqueza", o que a opção de Strauss, de traduzir khrematistikós por money-makers, denuncia é sua opção por sublinhar como característica dessa classe a busca por lucro.

29 STRAUSS, 1978, p. 109. Cf. PLATÃO. Cf. República, 390d. Pereira traduz khrematistikós por "classe negociante" e Chambry por "mercenaires". Cf. CHAMBRY, Émile (Trad.). La République. Introduction de Auguste Diès. Paris: Les Belles Lettres, 1996. v.1. p. 98 e PEREIRA, 1987. p. 111.

30 Cf. REEVE, C. D. C. Philosopher-Kings: The Argument of Plato's Republic. Princeton: Princeton University Press, 1988.

http://www.ucp.br/html/joomlaBR/synesis/synesis.htm 
o que há de mais pernicioso, inclusive para a boa prática das artesanias ${ }^{31}$.

O que poderia justificar essa opção é, de um lado, a passagem em que se procura a justiça na cidade já purgada dos excessos e que deve possuir as virtudes ${ }^{32}$ (e na qual se menciona realmente uma classe "negociante") e, por outro, a aplicação por demais estrita da caracterologia apresentada no livro IX, segundo a qual há os amantes do ganho, os amantes das honras e os amantes do saber $^{33}$.

Quanto à primeira passagem, o que se pode dizer é que sua correta interpretação é fundamental para determinar como toda a República deve ser lida. Strauss, parece fixar essa passagem como aquela que determina sua interpretação, pois refere-se à classe dos artesãos sempre como money-makers.

O que é preciso notar sobre a identificação da justiça na cidade, assim, como sobre a identificação das outras virtudes, é que, na altura em que são aí identificadas, estão longe de poderem ser fixadas e que nem sempre nessas passagens Sócrates refere-se à cidade que está construindo com o lógos. ${ }^{34}$

Quanto à caracterologia do livro IX, o que é preciso entender é que se refere às naturezas e que não é justo fixá-la como dizendo respeito às três classes da cidade, pois as classes da cidade são compostas de homens e homens não são apenas naturezas, mas a síntese de natureza e educação.

Sobre a primeira passagem em discussão, note-se que ao anunciar o que se seria a injustiça na cidade Sócartes tem de recorrer a uma cidade hipotética que não pode ser a cidade construída com o lógos:

Mas, quando, penso eu, um homem for, de acordo com a sua natureza, um artífice ou negociante qualquer, e depois de exaltado pela sua riqueza, pela multidão, pela força, ou por qualquer outro atributo desse gênero, tentar passar para a classe dos guerreiros,

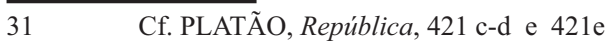

32 PLATÃO. República, 434a-b. infra.

33 PLATÃO. República, 581c.

34 Para uma discussão desse ponto, ver MOTTA, 2010. Cf. PLATÃO. República, 427c-432b. 
ou um guerreiro para a classe dos chefes o guardiões, sendo indigno disso, e forem esses que permutem entre si instrumentos e honrarias, ou quando o mesmo homem tentar exercer estes cargos todos ao mesmo tempo, - nesse caso penso que também acharás que esta mudança e confusão serão a ruína da cidade ${ }^{35}$.

Ora, na cidade construída com o lógos não poderia haver um artífice ou negociante enriquecido, simplesmente porque a riqueza foi excluída da cidade. Se essa cidade hipotética referida não é a cidade no lógos, deve-se ter muito cuidado ao fazer a transição para a próxima passagem, pois ela pode bem ser apenas o termo com o qual se compara essa primeira e pode ser também uma hipotética cidade que tivesse a mesma estrutura da polis no lógos, apenas para que fique evidente que se isso acontecesse lá, também lá haveria injustiça. Sócrates pergunta a Gláucon;

E agora digamos a inversa: se a classe dos negociantes [khrematistikós], auxiliares e guardiões se ocupar de suas próprias tarefas, executando cada um deles o que lhes compete na cidade, não se verificaria o contrário do caso anterior, a existência da justiça, e isso não tornaria a cidade justa? ${ }^{36}$

Diante da resposta afirmativa de Gláucon, e considerando-se que haviam declarado ter encontrado a justiça na cidade, não deixa de ser surpreende que Sócrates manifeste dúvida:

Não o afirmemos com toda a segurança, mas se reconhecermos que esta concepção, passando a cada indivíduo em particular, também aí será justiça, já concordaremos - pois por que não o diremos? Caso contrário, então examinaremos qualquer outra questão. Mas

$35 \quad$ PLATÃO. República, 434a9-b7.

36 PLATÃO. República, 434c7-11.

http://www.ucp.br/html/joomlaBR/synesis/synesis.htm 
agora, levemos a cabo esta investigação, da qual pensávamos que, se tentássemos contemplar a justiça num de seus maiores possuidores, antes de a vermos aí, se tornaria mais fácil vê-la num indivíduo. E pareceu-nos que tal possuidor era a cidade, e assim fundamos uma o melhor possível, perfeitamente cientes de que a justiça estaria nela, se fosse boa. Aquilo que aí se nos revelou, vamos transferi-lo para o indivíduo, e se se acertar, bom será. Mas se a justiça se manifestar como algo diferente no indivíduo, regressaremos novamente à cidade, para tirar a prova, em breve, comparando-as e friccionando-as uma contra a outra, como de uma pederneira, faremos saltar a faísca da justiça. E, depois de ela ter se tornado bem visível, fixá-la-emos em nós mesmos. ${ }^{37}$

O que Sócrates indica aqui é que não é possível compreender a justiça, como, de resto, não é possível compreender completamente nenhuma das virtudes na cidade, senão pela compreensão do que é homem, ou mais especificamente, de quais as forças em relação na alma humana e de qual a relação apropriada entre elas. É só a compreensão adequada dessas relações que permitirá um correto entendimento da analogia entre cidade e alma na República.

Também quanto à compreensão da alma seria extremamente prejudicial para o entendimento da obra que se estabeleça uma analogia muito estrita entre as três classes da cidade e os três elementos presentes na alma.

Uma analogia assim implicaria que há nos homens um elemento racional que se desenvolve apenas tal como se desenvolve a classe dos filósofos governantes, ou seja, alimentado com os conhecimentos que conduzem, por exemplo, ao conhecimento das $\operatorname{Ideias}^{38}$, um elemento irascível que auxilia o elemento governante e que deve ser desenvolvido na classe que lhe corresponde e um elemento apetitivo que deve ser governado tal como uma classe supostamente amante do lucro deve ser governada pelas duas primeiras.

Parece ser essa mesma a concepção de Strauss:

37 PLATÃO. República, 434e-435a.

38 Deve-se ter em conta que, para a classe dos guardiões-governantes, há uma educação suplementar, que inclui as disciplinas matemáticas e a dialética, além da educação primária.

http://www.ucp.br/htmlljoomlaBR/synesis/synesis.htm 
Um homem é justo se a parte racional da sua alma é sábia e governa (441e) e se a parte irascível, sendo submissa e aliada da parte racional lhe presta assistência no controle da multiplicidade de desejos os quais se tornam quase inevitavelmente desejos por mais e mais riquezas. Isto significa, portanto, que apenas o homem no qual a razão propriamente cultivada governa as outras duas partes propriamente cultivadas, isto é, o homem sábio, pode ser realmente justo (442c); a alma não pode ter saúde se uma de suas partes, e especialmente a melhor, está atrofiada. Não é de se admirar então que o homem justo acabe se identificando com o filósofo (580d-583b). A classe dos money-makers e dos guerreiros não são verdadeiramente justas porque sua justiça deriva exclusivamente de uma habituação de uma forma ou de outra, distinguindo-se daquela que deriva da filosofia; consequentemente, no mais íntimo recesso de sua alma eles desejam a tirania, isto é, pela completa injustiça. ${ }^{39}$

Embora Strauss logo a seguir diga que os membros da boa cidade agiriam de modo muito mais justo do que os membros das cidades reais, a interpretação de Strauss deixa claro que exclui que os artesãos possam ter a justiça na alma.

A maneira como Strauss entende que se dá a temperança na cidade e nas diferentes classes também denuncia sua concepção de como se dá a analogia entre cidade e homem que acaba por exigir diferentes acepções para a temperança conforme a classe de que se fala:

Achar a temperança (moderação) não é tão fácil. Se ela significa o auto-controle no que diz respeito aos prazeres e desejos, é também prerrogativa de governantes e guerreiros (431b9-d3). Contudo também pode ser compreendida como sendo o controle do que é por natureza pior pelo que é por natureza melhor, isto é, aquilo através do que o todo está em harmonia, ou a concórdia entre os naturalmente superiores e os naturalmente inferiores sobre qual dos dois deve governar na cidade; a temperança assim compreendida

$39 \quad$ STRAUSS, 1978 , p. 109.

http://www.ucp.br/html/joomlaBR/synesis/synesis.htm 
perpassa todas as partes da cidade boa. Mesmo assim, à temperança falta a simplicidade e univocidade da sabedoria e da coragem. Uma vez que controlar e ser controlado são coisas diferentes, a temperança da classe superior difere da temperança da classe inferior. ${ }^{40}$

O que se propõe aqui, entretanto, é que a concepção da alma tripartite e das relações entre seus elementos seja a que segue:

Todos os homens possuem os três elementos da alma: logistikón (racional), thymoeidés (irascível) e epithymetikón (apetitivo). O logistikón, não é, como Strauss e outros comentadores supõem, apenas sede de conhecimentos associados à razão que calcula, raciocina ou "dialetiza", mas simplesmente sede de conteúdos pensados, os quais podem ser os já mencionados ou quaisquer outros, indo da imaginação poética às opiniões verdadeiras. Seria, portanto, sede da diánoia, que admite toda essa plasticidade. Entendido assim, esse elemento pode ser cultivado (para usar a expressão de Strauss) ou nutrido não apenas com matemática ou dialética, mas com valores.

O elemento epithymetikón é sede dos desejos entendidos como desejos dos bens ou valores sensíveis experimentados como bens pelos sentidos ou dos bens que, de alguma forma, se relacionam com o preenchimento dos desejos sensíveis. Esse elemento tende naturalmente a se fortalecer pelo contato com os bens capazes de suscitar prazer sensível e, portanto, se se deseja que não fique hipertrofiado é necessário restringi-lhe o acesso aos prazeres desnecessários.

O elemento thymoeidés não é sede de valores, mas uma força que pode ser cooptada tanto em favor dos valores sensíveis do epithymetikón quanto dos valores cuja sede é o logistikón. ${ }^{41}$

Tendo isso em vista é preciso reconhecer que há os homens que têm por natureza cada um dos três elementos predominante (vide caracterologia do livro IX), mas também há que se reconhecer que na República a educação deve

\footnotetext{
$40 \quad$ STRAUSS, 1978, P. 108.

41 Para um discussão detalhada dessas concepções, ver MOTTA, 2010.

http://www.ucp.br/html/joomlaBR/synesis/synesis.htm
} 
ser tomada como um elemento decisivo na maneira como esses elementos virão a se relacionar.

Numa análise superficial, o que se vê na educação pela mousiké e gymnastiké proposta por Sócrates na República é, por um lado, uma trophé (alimentação ou nutrição) dos elementos logistikon e thymoeidés, e, de outro uma a-trophé do epithymetikón. Quanto ao primeiro (o logistikón), se lhe apresentam desde a mais tenra infância valores ou bens, alimentando-o por todos os lados com o que é belo. Quanto ao segundo (thymoeidés), se lhe alimenta associando honra a esses valores, e, sendo esse último elemento amante da honra, o efeito é o de torná-lo aliado da razão que é a sede desses valores honrados. Assim, a razão torna-se a sede de uma hierarquia de valores que determinam as escolhas e, consequentemente, o modo de vida dos homens assim educados.

O elemento epithymetikón, por outro lado não recebe uma trophé, mas, antes, uma a-throphé. O que faz a educação pela mousiké e pela gymnastiké é, entre outras coisas, retirar do horizonte de experiência os prazeres desnecessários tanto do corpo quanto da alma e, assim, impede a hipertrofia desse elemento, não permitindo que chegue a opor resistência ao governo dos outros dois.

Aqueles educados assim, podem, portanto, ter uma alma justa, sem que isso implique, como quer Strauss, o pleno desenvolvimento do elemento racional como se dá no filósofo. Basta que esse elemento seja sede dos valores que determinam as escolhas, envolvam esses valores o conhecimento fundamentado do porque são bens maiores ou a simples opinião verdadeira quanto a isso. Ora, a justiça, como entendida na República, é a virtude pela qual, no caso do homem, a razão governa os desejos com o auxílio do elemento irascível.

Homens que atinjam esse tipo de relação entre os elementos da alma não serão homens que no intimo desejam a tirania porque sua opção pelos valores pelos quais optam é, neles, inculcada desde a infância não como uma informação qualquer, mas efetivamente como opção por valores a serem preferidos aos valores sensíveis.

O que o que se disse até aqui indica que uma saída para se resolver algumas aparentes contradições da República, e, no caso do tema em discussão,

http://www.ucp.br/html/joomlaBR/synesis/synesis.htm 
eliminar a injustiça de se chamar os artesãos da cidade no lógos de moneymakers, é a consideração de que a educação pela mousiké e gymnastiké nesta cidade destina-se a todas as classes.

A educação comum a todas as classes é a condição de possibilidade de certas características da cidade, como o fato de que a temperança perpassa todas as classes ou de que possa haver a passagem dos filhos de uma classe para outra ${ }^{42}$. Da mesma forma, a tese da educação exclusiva para os guardiões auxiliares e governantes deixa sem resposta a pergunta sobre o que fazer como os educandos que, em uma certa altura, não passem nos testes que determinam quem é realmente um guardião da cidade. Ora, estes têm de pertencer a alguma classe e devem ter alguma função na cidade e, portanto, devem pertencer à classe dos artesãos.

A concepção de Strauss sobre as relações entre as classes na cidade e sobre a analogia entre as classes e as partes da alma é, em última instância ditada por certos pressupostos que ele aceita sobre a República, sendo o mais importante para o que se se discute aqui o de que a educação pela mousiké e pela gymnastiké destinada apenas a auxiliares e governantes e que exclui a classe dos artesãos.

O que é mais lamentável na interpretação de Strauss sobre a República é que chame injustamente a classe dos artesãos de money-makers (produtora de riquezas) e tenha chegado a considerar, como hipótese, a tese da educação comum a todas as classes, que, se mantida, talvez eliminasse essa injustiça. Ele a considera justamente ao tratar da suposta dificuldade de se compreender a mobilidade de uma classe para outra na cidade presente em $415 \mathrm{a}-\mathrm{c}$ :

A fundação da boa cidade começou pela consideração do fato de que os homens são, por natureza, diferentes e ficou claro que isso significa que eles pertencem por natureza a diferentes classes. Eles são desiguais, em primeiro lugar, no que diz respeito à sua capacidade de adquirir virtude. A desigualdade que é devida à natureza e aumentada e aprofundada por seus diferentes modos de educação ou habituação e por seus diferentes modos de vida (comunista ou não-comunista), e que as diferentes partes da cidade boa desfrutam. Como resultado, a cidade boa vem a parecer-se

42 Cf. PLATÃO, República, 415a-c.

http://www.ucp.br/htmlljoomlaBR/synesis/synesis.htm 
com uma sociedade de castas. (...). Contudo na cidade boa da República, não é a descendência, mas os dons naturais de cada um que determinam a que classe pertencerá. Mas isso leva a uma dificuldade. Os membros da classe superior, que vive mediante de forma comunal, não devem conhecer quem são seus pais naturais, pois devem considerar todos os homens e mulheres que pertencem à geração mais velha da sua classe como seus pais. Por outro, lado as crianças bem dotadas da classe mais baixa, que não vive segundo o comunismo, devem ser transferidas para a classe superior (e vice-versa); uma vez que seus dotes naturais não são necessariamente reconhecíveis no momento de seu nascimento, elas podem vir a conhecer os seus pais naturais e podem mesmo se tornar apegados a eles; isso deveria torná-los inaptos a serem transferidos para a classe superior. Há três maneiras pelas quais essa dificuldade pode ser superada. A primeira é tornar a seleção pós-natal supérflua garantindo o resultado desejado pela seleção dos pais, e isso significa, é claro, dos pais da classe superior: todo filho de pais apropriadamente escolhidos é adequado para pertencer à classe superior. Essa é a solução subjacente à discussão, por Sócrates, do número nupcial (546c6-d3). A segunda maneira é estender o comunismo e - considerando-se a conexão entre modo de vida e educação - a educação musical para a classe inferior (401b-c, 421e-422d, 460a, 543a). Segundo Aristóteles (Política, 1264a13-17), Sócrates deixou não resolvida a questão sobre se o comunismo é limitado à classe superior ou se estende à classe mais baixa. Deixar essa questão sem solução estaria de acordo com a professada opinião de Sócrates sobre a menor importância dessa classe (421a, 434a). A ambiguidade concernente à educação musical é devida, em outras palavras, à comparação (por antecipação) da educação musical com a educação superior, comparada com a qual a diferença entre a educação dos guerreiros e a dos money-makers (negociantes) se torna insignificante. Contudo, de qualquer ponto de vista, exceto do mais elevado, essa diferença é, claramente, muito importante. Não se deve esquecer que a classe dos moneymakers, para dizer o mínimo, contém aqueles aos quais falta a boa natureza, mas são curáveis, de modo que não precisam ser mortos (410a1-4, 458d8-10). De acordo com isso, Sócrates alude à necessidade de histórias mentirosas a serem contadas, não aos guerreiros, mas àqueles insensíveis à beleza e à honra, ou seja, alude à necessidade de mentiras terrificantes e punitivas $(386 \mathrm{c} 1$, 387b4-c3), pois a massa desprovida de poder político pareceria 
grandemente necessitada de incentivo para obedecer com total adesão aos governantes. Só pode haver uma dúvida muito pequena de que Sócrates deseje limitar o comunismo e a educação musical à classe superior (398b2-4, 415e ff., 431b4-d3). Portanto, de modo a remover a dificuldade sob discussão, ele dificilmente pode evitar tornar o pertencimento de um indivíduo à classe alta ou baixa hereditário, violando assim um dos mais elementares princípios da justiça." ${ }^{\sharp 3}$

O que Strauss falha em perceber é que na cidade construída por Sócrates não só a justiça como a temperança, duas virtudes cívicas fundamentais na cidade, têm de estar presentes em todas as classes se se quer manter o que se diz sobre ela e sobre seu modo de vida.

Produzir essas virtudes em toda a cidade é o propósito mesmo da intervenção política de Sócrates como construtor de cidades e legislador. Essa intervenção se dá primeiro conhecendo os elementos que compõe a alma humana e em seguida atuando para produzir a relação entre eles que se identifica com a saúde e com a justiça. Essa atuação, um exame atento mostrará, se dá através da educação pela mousiké e gymnastiké que se estende por toda a cidade.

$43 \quad$ STRAUSS, 1978, p. 113-114. 


\section{Referências Bibliográficas}

\section{Edições/traduções de República}

ADAM, James (Ed.). The Republic of Plato. Notes, commentary and appendices by James Adam. Cambridge: Cambridge University Press, 1979, v. 2.

BACCOU, Robert (Trad.). La République. Introduction et notes par Robert Baccou. Paris: Garnier-Frères, 1996.

CHAMBRY, Émile (Trad.). La République. Introduction de Auguste Diès. Paris: Les Belles Lettres, 1996, v. 3.

PEREIRA, Maria Helena da Rocha (Trad.). A República. 11. ed. Introdução e notas de Maria Helena da Rocha Pereira. Lisboa: Fundação Calouste Gulbenkian, 1987.

PRADO, Anna Lia A.A. (Trad.). A República. Revisão técnica e introdução de Roberto Bolzani Filho. São Paulo: Martins Fontes, 2006.

SHOREY, Paul (Trad.). The Republic. London: Harvard University Press, 1994, v.

2. (The Loeb Classical Library, Plato, 5 e 6).

\section{Sobre República}

ANNAS, Julia. An Introduction to Plato's Republic. Oxford: Oxford University Press, 1981.

AVERRÓES. Exposición de la "República" de Platón. Traducción y estudio preliminar de Miguel Cruz Hernández. 5. ed. Madrid: Tecnos, 1998.

BENARDETE, Seth. Socrates'Second Sailing on Plato's Republic. Chicago: University of Chicago Press, 1989.

http://www.ucp.br/html/joomlaBR/synesis/synesis.htm 
DORTER, Kenneth. The Transformation of Plato's Republic. New York: Lexington Books, 2006.

FERRARI, G. R. F. The Three-Part Soul. In: . (Ed.). The Cambridge

Companion to Plato's Republic. New York: Cambridge University Press, 2008, p. 165-201.

2005

City and Soul in Plato's Republic. Chicago: University of Chicago Press,

HOURANI, G. F. The Education of The Third Class in Plato's Republic. The

Classical Quarterly, [S.1.], v. 43, n.1/2, p. 58-60, 1949.

KAHN, Charles H. Proleptic Composition in the Republic, or Why Book 1 Was Never a Separate Dialogue. The Classical Quarterly, [S.1.], New Series, v. 43, n. 1, p. 131-142, 1993. Em versão digital, acessível pelo JStor.

KRAUT, Richard. The defense of justice in Plato's Republic. In: (Ed.). The Cambridge Companion to Plato. New York: Cambridge University Press, 1992, p. 311-337.

LEAR, Jonathan. Inside and outside the Republic. In: KRAUT, Richard (Ed.). Plato's Republic: critical essays. Maryland: Rowman \& Littlefield Publishers, 1997, p. 61-94.

LORENZ, Hendrik. The Analysis of the Soul in Plato's Republic. In: SANTAS, Gerasimos (Ed.). The Blackwell Guide to Plato's Republic. 2nd. ed. Oxford: Blackwell Publishing, 2008, p. 146-165.

MAYHEW, Robert. Aristotle's Criticism of Plato's Republic. New York: Rowman \& Littlefield Publishers, 1997.

MORRISON, Donald R. The Utopian Character of Plato's Ideal City. In: 
FERRARI, G. R.F. (Ed.). The Cambridge Companion to Plato's Republic. New York: Cambridge University Press, 2008, p. 232-25.

MOTTA, Guilherme Domingues da. A educação como fundamento da unidade e da felicidade da pólis na República de Platão. Rio de Janeiro: IFCS/UFRJ, 2010.

MURPHY, N. R. The interpretation of Plato's Republic. Oxford: Clarendon Press, 1951.

NETTLESSHIP, R. L. Lectures on the Republic of Plato. London: Macmillan, 1920.

The Theory of Education in the Republic of Plato. Honolulu: University Press of the Pacific, 2003.

REEVE, C. D. C. Philosopher-Kings: The Argument of Plato's Republic. Princeton: Princeton University Press, 1988.

ROOCHNIK, David. Beautiful City: The Dialectical Character of Plato's Republic. New York: Cornell University Press, 2003.

ROSEN, Stanley. Plato's Republic: a study. New Haven: Yale University Press, 2005.

ROWE, Christopher. The Place of the Republic in Plato's Political Thought. In: FERRARI, G. R.F. (Ed.). The Cambridge Companion to Plato's Republic. New York: Cambridge University Press, 2008, p. 27-54.

TAYLOR,C. C. W. Plato's Totalitarianism. In: KRAUT, Richard (Ed.). Plato's Republic: critical essays. Maryland: Rowman \& Littlefield Publishers, 1997, p. 31-48.

WILLIAMS, Bernard. The analogy of City and Soul in Plato's Republic. In: 
KRAUT, Richard (Ed.). Plato's Republic: critical essays. Maryland: Rowman \& Littlefield Publishers, 1997, p. 49-60.

WHITE, Nicholas P. A Companion to Plato's Republic. Indianapolis: Hackett, 1979.

BRISSON, Luc. Leituras de Platão. Tradução de Sonia Maria Maciel. Porto Alegre: EDIPUCRS, 2003. (Coleção Filosofia, 166).

FERRARI, G.R.F. Plato and Poetry. In: KENNEDY, G. A. (Ed.). The Cambridge History of Literary Criticism. Cambridge: Cambridge University Press,1989, v.1., p. $92-148$.

GADAMER, H. G. Dialogue and Dialetic: Eight Hermeneutical Studies on Plato. Translated and with an introduction by P. Christopher Smith. London: Yale University Press, 1980.

GUTHRIE, W. K. C. A History or Greek Philosophy. Cambridge: Cambridge University Press, 1962, v. 5.

HAVELOCK, E. A. The Greek concept of justice. Cambridge: Harvard University Press, 1978.

. Prefácio a Platão. Tradução: Enid Abreu Dobránzsky. Campinas: Papirus, 1996.

IRWIN, Terence. Plato’s Ethics. New York: Oxford University Press, 1995.

KAHN, Charles H. Plato and the Socratic dialogue: The Philosophical Use of a Literary Form. Cambridge: Cambridge University Press, 1996.

MORROW, Glenn R. Plato's Cretan City: a historical interpretation of the Laws. With a new foreword by Charles H. Kahn. New Jersey: Princeton University Press, 
1993.

NAILS, Debra. The People of Plato: a prosopography of Plato and other Socratics. Indianapolis: Hackett Publishing Company, 2002.

NIGHTINGALE, Andrea W. Genres in Dialogue: Plato and the construct of philosophy. Cambridge: Cambridge University Press, 1995.

POPPER, Sir Karl R. A Sociedade Aberta e seus Inimigos. 3. ed. Tradução de Milton Amado. São Paulo: Itatiaia, EDUSP, 1987, v. 2. (Biblioteca de Cultura Humanista, 2-3).

ROBINSON, T. M. A Psicologia de Platão. Tradução e prefácio à edição brasileira de Marcelo Marques. São Paulo: Loyola, 2007.

ROOCHNIK, David. Of Art and Wisdom: Plato's Understanding of Techne. University Park: Pennsylvania State University Press, 1996.

SANTAS, Gerasimos. Plato and Freud: Two Theories of Love. New York: Basil Blackwell, 1988. . Goodness and Justice: Plato, Aristotle and the Moderns. Oxford: Blackwell publishers, 2001.

STRAUSS, Leo. The City and Man. Chicago: The Chicago University Press, 1978. . Studies in Platonic Political Philosophy. Introduction by Thomas L. Pangle. Chicago: The Chicago University Press, 1983.

TAYLOR, A. E. Plato, the man and his work. London: Methuen, 1960.

VLASTOS, Gregory (Ed.). Plato II: A Collection of Critical Essays. Ethics, Politics and Philosophy of art and Religion. Indiana: University of Notre Dame http://www.ucp.br/html/joomlaBR/synesis/synesis.htm 
Press, 1978.

Platonic Studies. 2nd. ed. New Jersey: Princeton University Press, 1981.

VOEGELIN, Eric. Order and History: Plato and Aristotle. Columbia: University of Missouri Press, 2000. (The Collected works of Eric Voegelin, v. 3).

\section{Edições/traduções de obras antigas}

CROISET, Maurice (Éd.). Hippias Mineur, Alcibiade, Apologie de Socrate,

Euthyphron, Criton. Paris: Les Belles Lettres, 1953. (Collection des Universités de France, Platon, t. 1).

IGLÉSIAS, Maura (Trad.). Mênon. Texto estabelecido e anotado por John Burnet. Rio de Janeiro: PUC-Rio; Loyola, 2001.

KURY, Mário da G. (Trad.). Política. 3. ed. Brasília: UnB, 1997.

NUNES, Carlos Alberto (Trad.). O Banquete, Apologia de Sócrates. 2. ed. Belém: UFPA, 2001. . (Trad.). Eutifron. Belém: UFPA, 1980.

. (Trad.). Fedro, Cartas, O Primeiro Alcibíades . 2. ed. Belém: UFPA, 2007.

. (Trad.). Filebo. Belém: UFPA, 1974.

. (Trad.). Ilíada. 2. ed. Rio de Janeiro: Ediouro, 2001.

. (Trad.). Leis, Epínomis. Belém: UFPA, 1980.

. (Trad.). Odisséia. Rio de Janeiro: Ediouro, 1997. 
(Trad.). Protágoras, Górgias, Fédon. 2. ed. Belém: UFPA, 2002.

OLIVEIRA, Francisco (Trad.). Cármides. Coimbra: Instituto Nacional de Investigação Científica, 1981. (Textos Clássicos, 12).

. (Trad.). Laques. Lisboa: Ed. 70, 1989. (Clássicos Gregos e Latinos, 2).

ROBIN, Léon (Trad.). Oeuvres Complètes. Traduction avec la collaboration de M. J. Moreau. Paris: Gallimard, 1940-42, 2 v. (Collection de la Pléiade).

\section{Sobre cultura, história e literatura}

BRANDÃO, Jacinto Lins. Oralidade, escrita e literatura: Havelock e os gregos. Literatura e Sociedade: Revista de Teoria Literária e Literatura Comparada. São Paulo, n. 2, p. 222-231, [199-?].

DETIENNE, Marcel. A invenção da Mitologia. Rio de Janeiro: José Olympio, 1992.

Os Mestres da Verdade na Grécia Arcaica. Rio de Janeiro: Zahar, 1988.

DOVER, K. J. Greek Popular Morality: In the time of Plato and Aristotle. Indiana: Hackett, 1994.

JAEGER, Werner. Paidéia, a formação do Homem Grego. Tradução de Artur M. Parreira. São Paulo: Martins Fontes, 1995.

KERFERD, G. B. The sophistic Movement. Cambridge: Cambridge University Press, 1981.

MARROU, Henri-Irénée. História da educação na antiguidade. Tradução de Mário Leônidas Casanova. São Paulo: E.P.U., 1990.

http://www.ucp.br/html/joomlaBR/synesis/synesis.htm 
VERNANT, Jean-Pierre. Mito e Pensamento entre os Gregos: Estudos de psicologia histórica. Tradução de Haiganuch Sarian. Rio de Janeiro: Paz e Terra, 1990.

\section{Index e léxicos}

BRISSON, Luc; PRADEAU, Jean-François. Vocabulário de Platão. Tradução de Claudia Berliner. Revisão técnica de Tessa Moura Lacerda. São Paulo: Martins Fontes, 2010.

CHANTRAINE, Pierre. Dictionnaire Etymologique de la Langue Grecque. Paris: Klincksieck, 1968, v. 4.

DES PLACES, E. Lexique de la Langue Philosophique et Religieuse de Platon. Paris: Les Belles Letres, 1964, v. 2.

LIDDELL, H. J.; SCOTT, R. A Greek English Lexicon. Oxford: Oxford University Press, 1996.

PETERS, F. R. Termos Filsóficos Gregos. Tradução de Beatriz Rodrigues Barbosa. Lisboa: Fundação Calouste Gulbenkian, 1977. 